\title{
A Field Study on the Acceptance Characteristics of Korean Drama by Thailand Viewers
}

\author{
Seung Kwan Ryu1)
}

\begin{abstract}
This study explored the general viewing behaviors and characteristics of Korean dramas' reception on Thailand viewers through focus group and in-depth interviews. Specifically, this study investigated the reasons why they watch Korean dramas, the difference or cultural proximity with local contents, and what kinds of factors are related or interwoven. As a result, this study found several major factors affecting Korean drama viewing, such as cultural differences rather than proximities, content quality in terms of reality, diversity, storytelling, appearance of actors as well as attractiveness, and lastly, 'Koreanness'. Thailand viewers tend to watch Korean dramas mainly because they are excellent in scenes and provide superior quality of contents and characters. More importantly, they seem to watch diverse Korean dramas, for instance, several genres of dramas dealing with politics and society, especially because they think these factors are lacking in Thailand dramas. In conclusion, this study found that Thailand viewers tend to satisfy their emptiness and seek unfulfilled desire to overcome their social status and struggle against deep economic polarization in their country.
\end{abstract}

Keywords: Drama Reception, Korean Wave, Thailand, Korean Drama, Cultural Differences

\section{Introduction}

It has been quite a long time since Korean dramas, movies and K-pop were loved by locals in Northeast Asia, including with China and Japan. However, recent exchanges between the two countries have not been brisk due to historical, political, military and economic issues. When the Chinese government banned Korean pop culture in July 2016, Korean content-companies have faced increasing difficulties. Nevertheless, several countries still like and actively visit Korean pop culture including Thailand. One of them is Thailand. Since Korea and Thailand officially established diplomatic relations in 1958, they have maintained and developed very close cooperative relations across multiple fronts, including politics, diplomacy, economy and culture[1].

Currently, Korean language is being taught at more than 40 universities in Thailand,

Received(October 30, 2019), Review Result(1st: November 25, 2019, 2nd: January 09, 2020), Accepted(March 25, 2020)

1) (Professor) 48520 Dept. Media Communications, Tongmyong Univ., 428 Sinseon-ro, Nam-gu, Busan, Korea email: sryu@tu.ac.kr 
including eight universities where major courses are offered. In 2008, Thailand's Education Ministry decided to educate Korean language in middle and high schools as a second language. Since the Korea-Thailand summit in 2011, the Korean government has dispatched about 60 Korean teachers to secondary and high schools in Thailand every year. The number of middle and high school students studying Korean as a second language is about 100,000, and more than 20,000 of them are Thai[2].

Like other countries in Southeast Asia, the Korean Wave in Thailand began with Korean dramas. In 2003, the popular drama "Autumn Fairy Tales," which was rerun three times, was aired, and the Korean Wave in Thailand has been in full swing since then. Historically, although relatively late in life compared to Japan and China, the Korean Wave in Thailand has an unlimited growth engine and is affecting various aspects of Thailand's society, culture and economy[3].

The K-pop trend led to the popularity of the Korean Wave later in the second half of the decade. According to a survey on an associative image about Korea, 16.6 percent of consumers of Korean Wave content thought of K-pop, climbing from seventh to third rank in 2016[4].

Despite the steady pace of the Korean Wave in Southeast Asia, the Korean media still tends to focus on China, Japan and Europe. Also, recent series of phenomena calls for a fundamental overhaul of the Asian region. For example, existing Korean Wave-related studies based on cultural proximity tend to revolve around China and Japan, while regional case studies in Asia are lacking. Research on Thailand, which has great potential among Southeast Asian countries and has deep traditional diplomatic relations with South Korea, is relatively meager. Furthermore, 'cultural proximity', 'reductionism economy' point of view, and studies which mainly focuses on 'communication effect' without deep reflection on cultural meaning, have been attempted in studies related to the Korean Wave. Therefore, exploring historical, cultural and economic aspects in Southeast Asia based on social differentiation would be more necessary[5].

\section{Review of Previous Studies}

\subsection{Current Status of Korean Wave and Program Utilization in Thailand}

Iwabuchi argues that in Asia, Japanese pop culture reflects western hegemony[6]. At the same time, it shows the modernity of Asia to the younger generation in the region through the frequent portrayal of mega-cities such as Tokyo, Hong Kong and Seoul in news and pop 
culture as backgrounds strengthens the new East Asian cosmopolitanism.

http://dx.doi.org/10.21742/apjcri.2020.04.04

The Asianization constructs an imagined sense of cultural proximity, which has been introduced to Japan, Thailand, Singapore, Indonesia and Vietnam, where Korean dramas are creating visual images based on their cultural proximity to Korea[7]. For example, Korean dramas, especially those with economic affluence and globally merged and projected can be replaced by traditional aesthetics[8].

On the other hand, Thailand is the sixth largest export market in Asia after Japan, China, Taiwan and Hong Kong; and the sixth largest worldwide, including the United States. But the exchange of broadcasting contents between Korea and Thailand shows that the export volume of 2015 has decreased compared to 2014 along with the imbalance between exports and imports. With regards genre of broadcasting content exported and imported between countries for two years, Korea's broadcasting contents were mainly dramas (5,002 in 2014 and 2,951 in 2015), followed by entertainment (1,443 in 2014 and 925 in 2015)[9].

In summary, entertainment programs, including Korean dramas, have been gaining popularity in Thailand, but the number of Korean dramas aired by Thai broadcasters has continued to decline in recent years. Also, while Thais watch Korean dramas on TV, most young Thais are watching Korean dramas on the Internet in addition to TV with increasing percentage.

\subsection{Preference Factors and Influence Factors for Korean Drama}

Thai people's favorite genre of pop culture was TV dramas (64.6 percent). Both men and women prefer Korean pop culture. But women rather than men, and upper-income earners have the highest positive rates for TV dramas among all age groups[10].

It is estimated that Thais like Korean movies and dramas because they are familiar with Asian themes and content as an Asian culture. Thailand is a society that values humanism, patriarchal family relations, and respect for ancestors because its geographical location has been greatly influenced by Indian Buddhist culture and Chinese Confucian culture, adjacent to India and China. Thais with such Buddhist and Confucian values claimed that their cultural proximity or affinity allowed them to accept the Oriental materials and content of Korean media contents without a sense of disapproval[11]. The advantage of Korean dramas preferred by Thais was that it was outstanding in image quality with its high-quality screenplay, background setting, camera work, and beautiful background music in terms of plot and composition[12].

Meanwhile, a study that analyzed the impact on the attitudes of each content by type of 
Korean contents showed that the consumption attributes of all drama content had a significant impact on the attitudes of drama content. Ranking the factors in a Korean drama, the importance of 'content attributes' (funny story, solid story structure, cinematography of works) turned out most important. Second is the 'character attributes' (the appearance of K-pop stars). The last is the 'cultural attributes' (the combination of Western culture with contemporary culture, traditional and modern combination, and cultural proximity. In other words, this study confirmed that content quality is the most important for the consumption of Korean contents[13].

If we draw the implications through the research review, dramas have been the driving force behind the Korean Wave and have the greatest impact on the formation of a favorable national image or brand image in Thailand. In addition, while there are cultural proximity, the advantage of Korean dramas seems that mixed factors such as the cultural difference and peculiarities inherent in the content itself. For example, image beauty, modernity, story or actor's appearance and charm, are acting in a very complex way.

\section{Research Problems and Methods}

Although Korean dramas have been the driving force behind the first-generation Korean Wave in Southeast Asia, including Thailand, it seems meaningful to analyze the preference factors and characteristics of acceptance at this point as they are in a slump compared to K-pop. Therefore, this study will analyze the characteristics of Thai viewers' acceptance of Korean Wave content more deeply, focusing on the use of Thai viewers' use of broadcasting contents (mainly dramas). Thailand's video content consumption is now online similar to Korea, and the use of social media has become a major factor driving the Korean Wave in general. In this regard, the impact of using Internet and social media in viewing Korean drama will also be investigated.

Based on the implications of previous researches, this paper will look at the characteristics of Thai people's general use of Korean dramas (major ways to use, use patterns, K-pop preferences, and using social media with watching dramas). It will also investigate the main motivations and reasons of Thais about Korean dramas.

To investigate the research problems, this study conducted in-depth interview with Thai viewers who were deemed highly interested in Korean Wave and Korean TV dramas. In-depth interview was conducted by adding subjects through snowball techniques after inviting people interested in Korean dramas introduced through local Korean reporters, company residents and 

private operators. The in-depth interview was conducted three times at a Korean Restaurant and the Korean Cultural Center in downtown Bangkok for about two weeks in early November 2019. The focus group interview was conducted on 10 students of the Korean language course at the Thammasat University in Rangsit campus on November 3, 2019. Prior to the full interview, a questionnaire asking for demographic information was distributed. Through a semi-structured method, participants were asked the general acceptance behavior and overall recognition of Korean dramas.

The study seeks to find out how acceptance of Korean dramas, one of Korea's most representative pop culture, is taking place at a local site in Thailand. The participants were labeled with letters, as shown in Table 1 below.

[Table 1] Interviewees and Focus Group Interviewees

\begin{tabular}{|c|c|c|c|c|}
\hline & occupation & age & $\begin{array}{l}\text { academic } \\
\text { background }\end{array}$ & gender \\
\hline A & company staff & 41 & postgraduate & female \\
\hline B & graduate student & 26 & & female \\
\hline C & $\begin{array}{l}\text { high school } \\
\text { student }\end{array}$ & 18 & & female \\
\hline $\mathrm{D}$ & graduate student & 26 & & female \\
\hline $\mathrm{E}$ & a clerk for a firm & 24 & college graduate & female \\
\hline $\mathrm{F}$ & high school teacher & 36 & college graduate & female \\
\hline G & university student & 21 & & female \\
\hline $\mathrm{H}$ & university student & 20 & & male \\
\hline I & university student & 22 & & female \\
\hline $\mathrm{J}$ & university student & 22 & & female \\
\hline K & company staff & 34 & college graduate & female \\
\hline $\mathrm{L}$ & graphic designer & 24 & college graduate & female \\
\hline
\end{tabular}




\begin{tabular}{|c|c|c|c|c|}
\hline $\mathrm{M}$ & company staff & 37 & college graduate & female \\
\hline $\mathrm{N}$ & company staff & 28 & college graduate & female \\
\hline $\mathrm{O}$ & company staff & 39 & college graduate & female \\
\hline $\mathrm{P}$ & university staff & 58 & postgraduate & male \\
\hline $\mathrm{Q}$ & personal business & 53 & college graduate & male \\
\hline
\end{tabular}

\section{Characteristics and Preference Factors of Korean Drama Acceptance}

\subsection{General Utilization Characteristics of Korean Dramas}

\subsubsection{Viewing Method}

Thais watch Korean dramas on terrestrial and cable TV programs, but these days, they are watching various paid and free online channels. This includes viewing on websites K-series and VIU, OTT services Line TV and Netflix, and streaming on YouTube.

"I've seen it a couple of times with the VIU application. Many dramas are provided by VIU, however it is expensive to sign up for membership and have to pay money every month.

I prefer watching through Netflix because the drama subtitles provided by Netflix are easier to understand and have better picture quality. In addition, the fact that I can choose Thai subtitles or Thai dubbing in language settings is a reason why I prefer Netflix, although it is a costly method." (Interview B).

\subsubsection{Viewing Quantity}

Although the average daily or monthly use was not calculated in this kind of qualitative research, it seems that most watches two to three days a week, or more than two to three hours a day. If they do not watch it every day, they watch it all day, which is very addictive.

"I watch one drama about once a month. But once I start watching it, I watch it 24 hours a day to see it through at once. Even if I fall asleep for two to three hours, I get up again, wash up, eat, and watch again." (interview B). 


\subsubsection{Using SNS (Twitter, Blog, Facebook, Instagram, etc.) and Watching Korean Dramas}

The responses from many Thai viewers confirmed that SNS use is having a great impact on watching Korean dramas. This phenomenon is seen as a natural inducement to watch dramas. Some people said they watch the drama because they know the approximate story of the drama in advance through SNS sharing or because they can choose to see it after checking their ratings beforehand. In this regard, SNS sharing seems to be having a significant impact on the interest and viewing of Korean dramas.

"Because people get new information through SNS and share their leisure life, they are naturally interested in sharing Korean dramas on SNS. Also, SNS is a major means of accessing Korean drama updates." (interview A).

"SNS sharing has a huge impact on the interest and viewing of Korean dramas. Especially, sharing is very active through Twitter and Facebook. For example, if someone talks about and shares a scene in a Korean drama, they naturally get interested and searches for the drama. Also, Thai people capture a scene of a drama with Thai subtitles and use it as stickers on SNS such as Line or Kakao Talk." (Interview B).

\subsubsection{Mutual Influence with K-pop}

Looking at the interview responses, there are some who said they like both Korean dramas and K-pop equally. Although Thai viewers had a high preference for K-pop, their preference for Korean dramas also remained high. The study did not verify whether the generation preference differences were statistically significant. But in general, the younger generation, including those in their 20s, had higher K-pop preferences, which enabled them to confirm that the generation-by-generation differences existed as expected. The following response is an example of a preference for K-pop over dramas.

"I like K-pop more. Because there's a beginning and an end for drama, and it's over after drama, but in K-pop, it's not over. So I can continue to support and like it. Also, songs can be enjoyed without Thai subtitles to understand." (Interview B).

Preference for K-pop appears to be having a positive effect on Korean drama viewing through the appearance of a favorite singer or actress in a drama or OST. For instance, if it was a drama played by a favorite singer or actor, viewers tended to watch the drama to support him or her.

"If my favorite K-pop singer acts in a drama, it has a big impact on watching the drama. One more thing that could have an impact is that the singer sang the OST of the drama. I 
find out which episode the OST my favorite singer sings on, and if I like the story, I keep watching it." (Interview B).

Hence, K-pop idol's appearance in dramas, especially for younger viewers, seems to have a profound effect on attracting Korean drama viewing.

"I joined in SHINee's official fan club, and it's active now. In SHINee's case, I watched the drama as a fan of SHINee because all the members participated in it as actors or as OST. For example, SHINee Stand by me (Ost. Boys Before Flowers), SHINee Green Rain (The Queen's Classroom), and Jonghyun \& Taemin That Name (Who Are You School 2015). If the drama involves such a favorite K-pop singer, it has a huge impact on like me." (Interview B).

"I'm a fan of K-pop singer GOT7 and a fan of Lee Seung-gi. I always watch the drama with my favorite singer or actor. Regardless the drama is funny or not, it's more important whether the character is someone I like or interested in." (Interview C).

\subsection{Characteristics of Acceptance of Korean Dramas}

The most impressive dramas and dramas currently being watched were "My Love from the Star," "Cloud Drawn Moonlight," "Guga's Book," "The K2," "Heirs" and "W". Dramas which they are watching were very diverse ranging from "Hotel Del Luna" to "Nogdujeon" and "Vagabond". There are several types of reasons to prefer.

\subsubsection{Actor Factors - The Appearance, Acting, and Charm of a Preferred Entertainer}

"First of all, I like characters so I watch them. Currently, GOT7 is very popular in Thailand. So when K-pop singer (K-pop singer GOT7, Jackson) shows, I really want to watch it." (Interview D).

"If your favorite K-pop singer appears as a minor/star or a drama with a favorite actor, you watch it to cheer them on. (For example, because I like actor Lee Jong-seok, I watched all the dramas featuring Lee Jong-seok (i.e. the latest drama 'W')." (Interview B).

\subsubsection{Story Factors - Fun, Interest, Diversity and Reality}

First, Thai viewers watch Korean dramas that show various aspects of Korean society. They think the story is so realistic that it expresses reality very well. They also think it describes the social culture of Korea in a realistic way.

"I like the way Korean dramas unfold their stories. This is because the flow of the story is realistic and it depicts every aspect of a certain role/job well. We can see various aspects of 
Korea. I think it's different from a Thai drama that emphasizes only love stories rather than reality. For example, when the male lead character in a Thai drama who is the president of a company, he doesn't work every day and goes out to eat with the heroine. Meanwhile, the real work is shown in Korean dramas, and even describes the job in great detail." (Interview B).

"The story is interesting and addictive. It provides a more realistic description of the phenomenon of social culture than Thai dramas, which enable you to gain more knowledge of Korean social culture." (Interview F).

"I think Korean dramas are very realistic compared to Thai dramas. It seems to show Korean society well and shows various aspects of Korean society compared to Thai society." (Interview N).

Some also say that it is good to watch various genres and to shed light on various professions and characteristics of society. Some say that social-replicating dramas are a genre that is hard to see in Thailand and that they get proxy satisfaction. Some pointed out, "It's not a soap opera like a Thai drama." (Interview M).

"Korean dramas have a variety of genres compared to Thai dramas." (Interview E).

"The story is complicated, and the unpredictable twist is attractive. In particular, it is interesting to portray the world of professionals such as lawyers in a realistic way. The drama "Return," which delves into corruption among rich people such as doctors, private foundations and executives of conglomerates, is also refreshing. I receive proxy satisfaction as it charges them for their misdeeds." (Interview P).

"I really enjoyed watching the drama 'Aides'. The drama seems to show the dark side of South Korea's political reality. It was regrettable that the righteous protagonist resisted to face real power but seemed to compromise with the enormous evil forces. Such dramas are hard to watch in Thailand. Most Thai dramas are about passion or revenge. Many are far-fetched and unnatural." (Interview Q).

\subsubsection{Cultural Differentiation Factors - Interests in Korean Society, Korean Culture, and Learning Korean}

Most of the responses in this category include they love to see Korean dramas because they like Korea. For example, "I enjoy watching Korean dramas because Korean culture is beautiful." (Interview I) and "because I like Korea, this is why I have an interest in Korean." One of the interesting answers is, "I'm going to imitate the Korean character in dramas.", and "I'm going to admire Korea." 
"I usually watch because it is a Korean drama. Also I enjoy watching them because I have a lot of interest in Korean. I think it can also be a practice process of listening to Korean through watching Korean dramas and further communication in Korean." (Interview F).

"Because I like Korea, I am interested in Korean culture. So I am currently studying Korean through Korean dramas." (Interview H).

Similarly, "The story is different from Thailand. It seems to be made from a new perspective." (Interview K), "Korean dramas are culturally different from those of Thailand, and I like them because they show different cultures." (Interview P), which can be viewed preference factors in terms of cultural differences.

\subsubsection{Visual Image Beauty, Completeness, and Modernity}

Other factors that favor Korean dramas were visual image beauty, completeness and modernity. These factors are partly overlapping with the above-mentioned content factors (actors and story factors) or cultural factors. But what is important here is that while a sense of homogeneity based on cultural proximity may be partly inherent, cultural differences from Thai dramas, such as images and technological elements containing beautiful nature and modern characters and backgrounds shows why they prefer Korean dramas.

For example, "Video is Beautiful." (Interview E, J, K and N), "Overall, it is more complete and editing skills are better than Thai dramas." (Interview K), and "Korean dramas are preferred because they have many beautiful places and come with various seasons in the background." (Interview N), "What makes Korean dramas different from Thai ones is that the plot is not obvious. It is natural, and it is more modern than Thai dramas." (Interview O).

\section{Conclusions}

The results of the research show that Thai people watch Korean dramas through terrestrial or cable TV programs, but more recently, they are watching Korean dramas through paid or free online channels on a PC or mainly mobile phones. In particular, the characteristics of SNS, which have active sharing functions, are found to be having a significant impact on the interest in Korean dramas and their continued viewing. Considering responses, drama viewing is not very much affected by K-pop's popularity in the prevailing mood. However, when a favorite singer appears in a drama or participates in an OST, it seems quite sure that it has a positive impact in strengthening Korean drama viewing. 


\begin{tabular}{|c|c|}
\hline Major Factor & Specification \\
\hline Actor/Actress & $\begin{array}{c}\text { Appearance, acting, charm of a preferred } \\
\text { entertainer }\end{array}$ \\
\hline Story & Fun, interest, diversity, reality \\
\hline Cultural differentiation & $\begin{array}{c}\text { Interests in Korean society, Korean culture, and } \\
\text { learning }\end{array}$ \\
\hline Visual image beauty, completeness, modernity & \\
\hline
\end{tabular}

Next, the motives and advantages of watching Korean dramas recognized by Thai viewers seem to be very diverse and complex. Although extracting the dominant factors from them is not easy, the results of interviews provide several important implications. Most notable reason as the motive for watching Korean dramas can be seen as factors resulting from content excellence and cultural differentiation such as the fun of the story, diversity, higher realism than Thai dramas, solid composition, and mechanics that closely woven various aspects of Korean society. In addition, the actor's appearance, charm and acting skills are equally important factors, making it hard to distinguish between content factors in terms of superiority. Content factors and the attractiveness of actors and looks are found to be consistent with other previous researches. However, the concept of "cultural proximity," which was also tried in previous studies, seems to have many limitations to explain Thai viewers' preference for Korean dramas. Although "cultural proximity" appears to be a relative value of being close compared to Western dramas, it is hardly seen as the sole or dominant factor.

In other words, it seems more reasonable to regard "cultural proximity" as a relative emotion compared to Western (European countries or especially American dramas). Along this line of thoughts, this study can also confirm "cultural differentiation" rather than "cultural proximity" appears to play a greater role as a preferred factor for Korean dramas. The fact that only a small number of respondents expressed sympathy for Korean traditional cultural value supports this.

Among the main motivations and benefits of Korean dramas, the comments watching them "because I like Korea" and "because I already like Korean culture" is also noteworthy. To explain this differently, Thai viewers, who are in a country where the Korean Wave is 
maturing, often have cultural affinity through various acceptance of the Korean Wave that has already accumulated in the past.

In other words, Korea or "Koreanness" itself is the cause of interest in Korean dramas which motivated and led to a favorable impression. For Thai viewers whose Korean Wave has matured overall, the popularity and loyalty accumulated for Korean dramas through experience in watching Korean dramas will continue to lead to drama viewing. This means other factors in the process may be secondary, which means the "Koreanness" itself, serves as a comprehensive factor that has a preemptive impact on continuing to watch or raising preferences.

Considering K-pop's common concerns and stories among young people around the world such as BTS, Korean dramas are less universal since they are mainly made up of Korean people's participation based on Korean emotions and production techniques made in Korea. Despite the ambiguity of the concept, "Koreanness"(especially one perceived as "Koreanness" by Thai viewers) seems to be one of the most comprehensive and distinct factors that favor Korean dramas rather than K-pop.

Next, according to Stuart Hall's argument, viewers may largely be dominated by negotiated reading or acceptance. Thai viewers also appear to use Korean dramas as a base for satisfying their desire to address deficiencies that they do not meet with their own dramas through preference reading based on their respective demographic positions. In some cases, resistance to Thailand's dominant ideology seems to work in this process. The primary rationale for this inference can be found in such responses saying that because the Korean drama shows the political and social realities of Korea very realistically and sometimes critically. For example, many people said they prefer to present individual struggles against injustice or unfairness in political and social genres of dramas (e.g., "Aides," "Defendants" and "People's Opinions") and in various sectors or professions of society.

Thai viewers (mostly from middle classes and the underprivileged excluding some upper classes) seek an alternative to solving complaints and shortages accumulated in Thai society's political and social realities, which also is resulting in catharsis. The results are in line with Ainslie's view, which analyzed that Thai viewers living in an era of social polarization, including political upheaval and the provincial and rural divide, accept Korean dramas with Korean characteristics as a means of resisting centralized state control[5].

This study did not attempt to generalize the motive or acceptance characteristics of all Thai viewers because of the nature of qualitative study. It mainly targeted only those who are favorable to the Korean Wave, including Korean dramas. Also, there may be limitations in 
understanding deeper contextual meanings in the process of sharing meaning through interpretation. It would be meaningful in terms of presenting another discriminatory receptive feature for Thais' acceptance of Korean dramas with some synchronic as well as diachronic perspective in Thailand, a representative region where Korean Wave is far mature at the end of 2019.

\section{Acknowledgement}

This work was supported by Tongmyong University Research Grant(2019)

\section{References}

[1] H. S. Jung, Comparative Analysis on the National Images Perceived by Thai and Korean Students on Each Other's Country, Journal of International Area Studies, (2009), Vol.12, No.4, pp.451-474, UCI: G704-000636.2009.12.4.012

[2] H. K. Kim, M. J. Lee, Thai Studies in Korea: Trends and Issues, Asia Review, (2017), Vol.6, No.2, pp.297-336, DOI: 10.24987/SNUACAR.2017.02.6.2.297

[3] Korean Wave Content Yearbook, Thailand, (2015)

[4] E. J. Ryu, J. M. Byun, Social Media Use for the Continuation of "The Korean Wave of K-Pop" - Focusing on BTS' Activity Pattern -, Culture and Convergence, (2019), Vol.41, No.3, pp.167-218.

[5] M. J. Ainslie, K-dramas across Thailand: Constructions of Koreanness and Thainess by contemporary Thai consumers, The Asia-Pacific Journal, (2016), Vol.14, No.6, pp.1-15.

[6] K. Iwabuchi, Cultural Globalization and Asian Media Connections, Feeling Asian Modernities: Transnational Consumption of Japanese TV Dramas, Hong Kong University Press, (2004)

[7] U. Siriyuvasak, The culture industry and Asianization: The new 'imagined inter-Asia economy, Pop Culture Formations across East Asia, Jimoondang, (2010)

[8] S. Wanttanansupakul, The Attributes of Asian Popular Television Drama: The Case of Japanese, Taiwanese and Korean Dramas in Thai Television, Faculty of Communication Arts, Chulalongkorn University, Master's Thesis, (2008)

[9] H. J. Moon, A Study on Export, Exchange and Cooperation for Broadcasting Contents between Korea and Thailand, Global Cultural Content, (2018), No.33, pp.63-87, DOI: 10.32611/jgcc.2018.4.33.63

[10] Awareness of Korea in Southeast Asia, Korea South-East Asia Institute, (2010)

[11] S. S. Kim, M. J. Kim, Effect of Hallyu Cultural Products in Thai Society on Enhancement of Korean National Image and Intention to visit, International Journal of Tourism Management and Sciences, (2009), Vol.23, No.4, pp.101-125, UCI: G704-000941.2009.23.4.004 
A Field Study on the Acceptance Characteristics of Korean Drama by Thailand Viewers

[12] S. K. Ryu, Characteristics of Thailand Viewers on Korean Waves: Focusing on Korean drama's preferences and its Impacts on National Image, Korean Journal of Communication Studies, (2014), Vol.22, No.2, pp.181-201, UCI: G704-001501.2014.22.2.006

[13] Y. K. Kim, J. H. Choi, H. B. Lee, The Effects of Consumption Attributes According to Contents Types of Korea Wave On the Attitudes of Korean Wave and of the Nation Brand - Focused on Segmentation of Korean Wave Market -, The Journal of Cultural Policy, (2017), Vol.31, No.2, pp.163-191. 